\title{
Kansei engineering approach for the customers preferences of car design
}

\begin{abstract}
In todayôs business environment, all companies must prioritize their extraordinary consciousness to determine the customersô design preferences before producing a certain product since customer design has become the primary concern of the companiesômarketing strategy. This study is related to the characteristic of product design based on customer emotional preferences using óKansei Engineeringô with a mathematical approach. The approach used in this study is to identify and investigate the customer satisfaction through the customersôpreferences that are focused on the design of the car products. 5 Kansei words and 20 Multi-Purpose Vehicle (MPV) car designs (side view) were used as samples for this study. The design of the 20 cars are then manipulated into 12 curves using Bezier cubic equation, including the segmentation of the design profile. From the data gathered, the customerôs preferences towards the carố design can be identified through the variables of Bezier curve equation.
\end{abstract}

Keyword: Kansei engineering; Bezier curve; Mathematical approach 